Ingrid Urgelles

Pontificia Universidad Católica de Chile

ingrid.urgelles@gmail.com

Danilo Santos

Pontificia Universidad Católica de Chile

dsantos@uc.cl

\title{
Perspectivas múltiples del conflicto paramilitar en dos novelas colombianas recientes: Viaje al interior de una gota de Sangre (2011) de Daniel Ferreira y EI espantapájaros de Ricardo Silva Romero (2012)*
}

\section{Multiple Perspectives on the Paramilitary Conflict in Two Recent Colombian Novels: Viaje al interior de una gota de Sangre (2011) by Daniel Ferreira and EI espantapájaros by Ricardo Silva Romero (2012)}

\section{Resumen}

En este artículo se explora la representación paramilitar como violencia narrativa del así llamado Conflicto Armado Interno colombiano en dos novelas del siglo XXI: Viaje al interior de una gota de Sangre (2011) de Daniel Ferreira y El espantapájaros de Ricardo Silva Romero (2012). En ambos textos se relata la masacre de una población con el exterminio indiscriminado de hombres, mujeres, niños y ancianos. Las dos historias se elaboran a partir de perspectivas múltiples que incluyen tanto a las víctimas como a los mismos victimarios

* Este artículo forma parte del Proyecto de Investigación Fondecyt Regular N 1190475 "A punta de balas y excesos: marginalidad social y literaria en la nación neoliberal en narcorrelatos chilenos del siglo XXI", cuyo investigador principal es Danilo Santos y en el cual Ingrid Urgelles es coinvestigadora. 
como enunciadores. Este enjambre de voces establece una conexión con la masacre como experiencia de exterminio colectivo en que el perspectivismo permite también la inclusión de las masculinidades victimizadoras, particularmente con el grupo paramilitar. Este artículo pretende dar relieve al elemento 'literaturizado' del multiperspectivismo con que ambos novelistas colombianos afrontan el desastre de la masacre al otorgar una lectura implícita de evaluación ideológica a esta explicitación saturada del procedimiento literario.

Palabras claves

Novela paramilitar, Masacre, Pluralidad de voces o perspectivismo, Ricardo Silva Romero y

Daniel Ferreira.

\begin{abstract}
In this article we explore the paramilitary representation as a form of narrative violence of the so-called Internal Armed Conflict in Colombia in two XXI century novels: Viaje al interior de una gota de Sangre (2011) by Daniel Ferreira and El espantapájaros by Ricardo Silva Romero (2012). Both texts tell about the massacre of peoples, with the indiscriminate extermination of men, women, children and elderly men and women. The stories are articulated from multiple perspectives, which include both the victims and the murderers as enunciators. This swarm of voices establishes a connection with the massacre as an experience of collective extermination in which perspectivism allows for the inclusion of victimizing masculinities, particularly the paramilitary group. This article seeks to highlight the "literarized" element from multiperspectivism by which these Colombian novelists face the disaster of the massacre, providing an implicit reading of ideological evaluation to the saturated explicitness of the literary procedure.
\end{abstract}

Keywords Paramilitary Novel, Massacre, Plurality of Voices or Perspectivis, Ricardo Silva Romero and Daniel Ferreira.

\title{
1. Introducción: la violencia del conflicto armado interno
}

Para Colombia, la violencia fáctica no es nueva y ha contemplado principalmente tres ejes: la guerrilla, el paramilitarismo y el narcotráfico. En el caso de los dos últimos, ambos permeados a su vez de las acciones u omisiones del mismo Estado colombiano. Respecto de la denominación "paramilitares", es relevante mencionar que, al existir diversas hipótesis respecto de su creación, se vuelve complejo el intentar definirla. Mauricio Romero en su texto "Paramilitarismo y Autodefensas" de 2003, establece una diferenciación entre ambos grupos considerando paramilitares a "los grupos armados para realizar operaciones de limpieza política y consolidación militar, previas al dominio territorial de un área, mientras que autodefensa se refiere a las agrupaciones 
CATEDRAL TomAda: Revista de crítica literaria latinoamericana / Journal of Latin American Literary Criticism

Perspectivas múltiples del conflicto paramilitar en dos novelas colombianas recientes: Viaje al interior de una gota de Sangre (2011) de Daniel Ferreira y El espantapájaros de Ricardo Silva Romero (2012)

organizadas para defenderse de un agresor y mantener el control de un territorio" (22). De este modo, la distinción se encuentra en los fines y modo de funcionamiento. Gustavo Duncan (2006) considera que en la definición de paramilitares confluyen diversos factores, como el ser "fuerzas que el Estado organiza para llevar a cabo asesinato selectivo de opositores políticos, como grupo de mercenarios anticomunistas propios de la guerra fría, como ejércitos adscritos a un grupo de interés del corte de terratenientes y gamonales y como escuadrones de la muerte al servicio de narcotraficantes" (240). Para efectos del presente trabajo, hemos decidido adscribir a la denominación que hace Mauricio Romero de las agrupaciones paramilitares como "empresarios de la coerción”. Con ello, Romero se refiere a "empresarios en el sentido en que proveen de un producto - la violencia o la amenaza de violencia - y pueden actuar como agentes de otros o a título propio. Ellos intimidan, protegen, recolectan información, saldan disputas, dan garantías, hacen cumplir contratos y cobran impuestos, entre otras actividades" (34). En resumen, son un grupo de mercenarios especializados en el uso y despliegue de la violencia organizada, la cual se ofrece como mercancía a cambio de dinero u otro tipo de valores.

Hablar del fenómeno paramilitar en Colombia conlleva cierta complejidad pues tanto su evolución como su creación han sido objeto de diversas teorías ${ }^{1}$. Evidentemente, sea cual sea la hipótesis que se suscriba, el origen está vinculado estrechamente con el "conflicto armado", guerra cuya longevidad también es asunto discutible pues es posible considerar una continuidad entre el período llamado de la "Violencia" (1946) y el escenario violento de nuestros días, pese a que sus protagonistas hayan cambiado, o por el contrario, se podría plantear también una diferencia radical entre la Violencia de los años 40' y la violencia revolucionaria que emerge con la creación de la guerrilla en los años 60'. Entonces, el paramilitarismo surge en este contexto de violencia como una suerte de actor co-

\footnotetext{
${ }^{1}$ No existe un origen cierto y se ha hipotetizado respecto de si surgen directamente de los grupos de Autodefensas campesinas que repelían el asedio de la guerrilla, si fueron creados como ejército al servicio del narcotráfico o derechamente como brazo ilegal antisubversivo del Estado colombiano (Juan Pablo Cardona Cháves, "Tres hipótesis acerca del fenómeno paramilitar en Colombia").
} 
protagónico (Cardona), imponiendo una violencia sin límites y siendo, finalmente, el grupo criminal que más víctimas ha dejado. Si bien la creación de grupos armados paramilitares como tal es discutible, su expansión por los diversos territorios se produce principalmente entre mediados de los años $80^{\prime}$ y finales de los 90', culminando el proceso el 97' cuando el número de ejércitos habría aumentado a tal punto, que se agrupan bajo el nombre de Autodefensas Unidas de Colombia y a partir de ese momento, el conflicto armado colombiano cobra una intensidad sin precedentes en la historia de Colombia (Ronderos, 26). Son responsables de cientos de masacres, torturas y asesinatos de civiles, campesinos, sindicalistas, militantes de grupos políticos de izquierda, a quienes acusaban de ser colaboradores o seguidores de las guerrillas. Otros hechos violentos, como el desplazamiento forzado de miembros de numerosas comunidades, la intimidación, el acoso y la fuerza militar, eran los principales métodos utilizados para el despojo de tierras.

La novela colombiana se ha ocupado de estos temas de la violencia, pudiendo identificarse entre ellos diversos géneros como las novelas de desplazados, la sicaresca o novela del narcotráfico, la relacionada con la guerrilla y la que hace referencia a la violencia paramilitar. Es esta última la que se trabajará en el artículo, al explorar la representación de las masacres perpetradas por grupos paramilitares. Para lo anterior, se estudian dos novelas en las que se relata la aniquilación de una población, la matanza indiscriminada de hombres, mujeres y niños. Narrativamente, estos relatos no se reducen únicamente a la masacre, pero este modo de impartir violencia tiene una importancia radical en la construcción de las historias. Historias que son mostradas a partir de perspectivas múltiples que incluyen usualmente a las víctimas, y paradojalmente, a los mismos victimarios. Este enjambre de voces establece una conexión con la masacre como experiencia de exterminio colectivo y como procedimiento atestado de "literatura", en aparente 
CATEDRAL TOMADA: Revista de crítica literaria latinoamericana / Journal of Latin American Literary Criticism

Perspectivas múltiples del conflicto paramilitar en dos novelas colombianas recientes: Viaje al interior de una gota de Sangre (2011) de Daniel Ferreira y El espantapájaros de Ricardo Silva Romero (2012)

contradicción con la referencia en parte testimonial del origen de estos eventos 'literaturizados'?.

\section{Lo paramilitar y el género narrativo}

Aclarado ya lo que se entiende por "paramilitar", retornamos a la literatura, objeto del presente texto. A partir del año 2006, y en coincidencia con el episodio conocido como "parapolítica"3, surge una narrativa que se hace cargo del conflicto armado, pero específicamente de la mímesis de la violencia paramilitar. Las novelas relatan mayoritariamente episodios de masacres haciendo una suerte de síntesis de los eventos acaecidos en la realidad, intentando recrear el horror, la violencia y el desamparo que sufrieron habitantes de tantos pueblos que fueron exterminados. En las novelas asistimos a la destrucción gratuita, explícita y arbitraria de personas que sólo son espectadores del horror pero con recursos novelescos que lo distancian de lo documental y exponen procedimientos de gran preocupación estético-formal.

Esta narrativa, que se ha denominado formato de la violencia paramilitar (Cf. Santos y Urgelles 2018), tiene como hito canónico la novela Los ejércitos (2007) de Evelio Rosero. Este texto relata, desde el punto de vista de un viejo profesor llamado Ismael Pasos, la sucesiva intervención violenta de ejércitos sobre un pueblo imaginario llamado San José y sus habitantes. Se relata la muerte detallada de varios de los personajes de la novela: niños, mujeres y hombres que van siendo asesinados irracionalmente. Asistimos también a la descripción de una serie de prácticas de tortura y ensañamiento sobre los cuerpos. El pueblo termina desapareciendo pues se ha convertido en un verdadero campo de batalla de diversas fuerzas entre las que no se identifica con claridad si se trata de paramilitares, guerrilla o fuerzas del Estado, "El ruido se acerca, ¿y si es un ataque? Puede suceder

\footnotetext{
${ }^{2}$ Se habla de 'literaturizado' con el fin de relatar la representación literaria de aquella masacre que es realizada por estos autores con procedimientos de mucha estilización estética. Tal opción artística parece entrar en contradicción con el origen documental de las masacres realizadas por los grupos paramilitares en las localidades rurales.

${ }^{3}$ Escándalo político desatado por la obtención de los archivos computacionales del líder paramilitar Jorge " 40 ", en el que se revelan los vínculos económicos existentes entre políticos del gobierno de Uribe y agrupaciones de paramilitares.
} 
que la guerrilla o los paramilitares hayan decidido tomarse el pueblo esta noche, ¿por qué no?” (22). Si bien la estructura de la masacre es identificable respecto de eventos realmente acaecidos en la realidad, la indistinción o asimilación de la guerrilla a los ejércitos paramilitares restringe levemente la posibilidad ideológica de la novela como fuente documento-literaria ${ }^{4}$. La estetización del texto, la maximización de la perspectiva del letrado y la ausencia de la voz del victimario atenúan o neutralizan la carga política y dejan en un espacio de ambigüedad los orígenes de la violencia que se ejerce sobre el pueblo. Lo anterior no ocurre exactamente así -aunque la influencia se deja oír algo todavía en Ferreira- en el caso de las novelas que estudiamos aquí: Viaje al interior de una gota de sangre (2011) de Daniel Ferreira y El espantapájaros (2012) de Ricardo Silva Romero.

\section{La masacre y la literatura en el relato paramilitar}

\subsection{La masacre y su delimitación en las ciencias sociales}

Se utilizará aquí una definición de masacre propuesta por Jacques Sémelin desde la sociología": "Forma de acción las más de las veces colectiva de destrucción de no combatientes" (28). Esta se puede complementar con la perspectiva de los autores argentinos José Emilio Burucua y Nicolás Kwiatkowski para hablar de la representación de las masacres:

El asesinato masivo de individuos desarmados y sin posibilidad de defenderse, perpetrado con métodos excepcionalmente crueles, al que se suma un gran desprecio hacia las víctimas vivas y muertas, es un fenómeno que reaparece con frecuencia abrumadora en la historia humana. No nos referimos a todos los casos de muerte colectiva, tremenda por cierto, sino a un evento planificado con antelación, que tiene lugar en un espacio y sitio delimitados, y del que un grupo (más que un individuo) es

\footnotetext{
${ }^{4}$ Cuando aludimos a esto, nos referimos a que el origen identificable de la masacre paramilitar específica podría abrir un relato más ideológico con una elaboración documental. Pero con gran sorpresa, en general los relatos paramilitares adaptan estrategias muy "estetizadas". Rasgo al que no escapan las dos novelas referidas en este artículo.
} 
CATEDRAL TomAda: Revista de crítica literaria latinoamericana / Journal of Latin American Literary Criticism

Perspectivas múltiples del conflicto paramilitar en dos novelas colombianas recientes: Viaje al interior de una gota de Sangre (2011) de Daniel Ferreira y El espantapájaros de Ricardo Silva Romero (2012)

responsable intencional. La enorme disparidad entre víctimas y perpetradores, así como la magnitud de la degradación de aquéllas, indica la naturaleza horrenda de estas masacres históricas. (11)

Rescatamos algunos elementos de Semelin y Burucúa / Kwiatkowski: la masacre es una forma de violencia destructora, colectiva, horrorosa contra personas desarmadas, de gran crueldad, planificada y llevada a cabo en una localización específica. En muchos casos, la masacre se acompaña de genocidio con un componente racista ${ }^{5}$, matanza colectiva y asimétrica, sin posibilidad de respuesta. Desde la perspectiva literaria puede considerarse que la barbarie es contestada desde la 'masacre' estetizada o mímesis de aquella que plantean narrativamente en sus novelas Silva Romero y Ferreira.

Nada ni nadie imagina la masacre. [...]Y los primeros disparos al aire, que vienen de cinco furgones viejos, repletos de asesinos, de visita en el poblado como una marcha fúnebre que colecciona cadáveres, despejan la duda de si volverá a empezar una tragedia que empezó hace mucho tiempo. (Silva Romero 7)

"Nadie imagina la masacre", una suerte de "Fiat Lux" del universo novelístico nos adentra en el mundo de la masacre novelizada. Sin ninguna duda, los procesos y la dinámica de la masacre literaria son transformados en un nuevo evento que toma una función diferente a la de un texto documental. Por lo tanto, no la de aquella versión oficial 'reparadora de memoria' y sí en las antípodas de la política destructiva y silenciosa de los victimarios paramilitares. Es una nueva comunidad literaria que diagnostica con más interrogantes que certezas qué ha

${ }^{5}$ Como dice Aquille Mbembe, en estos espacios, que bien podrían ser campos de exterminio, el Estado de excepción se ha vuelto lo normal en los términos al detectarse prácticas de muerte que él ha denominado de "Necropoder" 
pasado allí y cómo se puede representar autorialmente al dotar a las víctimas de una memoria al mundo anónimo de las víctimas.

\subsection{Hacia una literatura de la masacre: la historia de los personajes victimarios y víctimas}

En el caso de la novela de Ferreira, la narración se abre con una escena cruenta: la matanza indiscriminada de todo un pueblo, justo cuando éste se disponía a elegir a la reina de belleza popular, por parte de un grupo paramilitar de encapuchados. Narrada a partir de un coro de voces de las víctimas por el que el narrador básico reconstruye las historias de cada uno de los personajes. Esto para que el lector tenga acceso a conocer quiénes eran y qué estaban haciendo antes de que ocurriese la masacre. El autor va tejiendo cuidadosamente las vidas de estos pobladores, al mostrar el clímax fatal desde diversos ángulos, siempre con detalles de las vidas cotidianas de los habitantes del pueblo. El primer capítulo relata la masacre, la toma del pueblo y el asesinato de la mayoría de sus habitantes. Luego, la narración se reinicia y comienza a relatar los hechos que llevaron a cada uno de los sujetos-víctimas a esa tarde sangrienta. En una suerte de rompecabezas, el lector debe ir engranando cada uno de los microrrelatos hasta construir la historia de la masacre. El logro estético de la novela se encuentra principalmente en este manejo del tiempo narrativo, su expansión y la reconstrucción de las historias que permite dar una identidad a cada una de las víctimas y así evitar el anonimato de los muertos. Esta humanización de los sujetos impide reducir la guerra a buenos y malos en tanto restos físicos, específicamente respecto de las víctimas anónimas. El narrador que, en un comienzo relata la masacre con una distante omnisciencia, va a ceder parcialmente la palabra a los personajes a medida que se van relatando sus historias. Así, el narrador se sumerge en la subjetividad de un niño, personaje central, que cada tarde acude al rio a espiar a una bañista que se ha convertido en objeto de su obsesión: Irigna Delfina, protagonista del siguiente de los capítulos. Luego, encarna la voz con la misma Delfina, una adolescente entregada por su madre al mafioso del pueblo, Urbano Frías. Este, un rico ganadero dueño de 
CATEDRAL Tomada: Revista de crítica literaria latinoamericana / Journal of Latin American Literary Criticism

Perspectivas múltiples del conflicto paramilitar en dos novelas colombianas recientes: Viaje al interior de una gota de Sangre (2011) de Daniel Ferreira y El espantapájaros de Ricardo Silva Romero (2012)

fortunas ilícitamente adquiridas, anda en busca de jóvenes de 14 a 16 años para saciar sus apetitos y que promete otorgar un buen futuro económico tanto para la madre como para la hija. La voz ahora es la de un profesor homosexual, alcohólico y solitario que dicta clases de historia a un grupo de alumnos que se aburren profundamente y, luego, de un cura italiano de izquierda cercano al pueblo y sus necesidades. Así, cada microrrelato se organiza de manera tal que se van desprendiendo unos de otros para contar, como un caleidoscopio, la masacre del pueblo.

Al contrario de las víctimas, en la novela de Ferreira los personajes paramilitares son anónimos y homogéneos, denominados por el narrador como los "encapuchados", "los "hombres", "el comando de a pie", "el pelotón sin rostro", "los verdugos" o "el comandante". Sin nombres, ni historias ni motivaciones, constituyen una fuerza irracional y asesina que sin piedad masacra a los personajes. En este sentido podría considerarse que constituyen una agrupación siniestra,

[El pastor Ezequiel] ve a los encapuchados que disparan en todas las esquinas, se encorva entre las balas que silban sobre su cabeza y, sin poner atención a ese ensayo general del fin del mundo, camina a toda carrera y va encorvado hacia la bocacalle más cercana, desprevenido del francotirador apostado con un G3 que dispara ráfagas de cinco tiros a todo lo que se mueva. (23)

Al igual que en Los ejércitos, Ferreira narra una masacre que podría ser cualquiera de las que ocurrieron en la realidad, una suerte de síntesis de todos los eventos de violencia referencia pero desautomatiza el silencio de la masacre rural convirtiéndolo en un evento "bullicioso". Encapuchados armados ingresan al pueblo, asesinan a los pobladores que se encontraban en la plaza en una fiesta popular y exigen la entrega del cura a quien se acusa de ser colaborador de la guerrilla. El sacerdote es sometido a un juicio de guerra, ejecutado en la entrada de la iglesia y con ello, los paramilitares abandonan la localidad. Las escenas finales 
de la masacre son de especial crueldad: el humo que sale del pueblo en llamas, los restos humanos sobre la plaza, el cuerpo de una mujer joven en la orilla del río y la silueta de un niño que cuelga de un árbol. Así, la escena mortuoria finaliza de este modo: "tres mil casquillos de balas disparadas y medio centenar de cuerpos yacen en el corazón del caserío, iluminados apenas por el brillo último del atardecer" (31). $\mathrm{Al}$ provenir de una fiesta, Ferreira ilumina desde ese ángulo las vivencias de los personajes y carnavaliza la experiencia de la muerte. La fiesta mortífera es acompañada de contradicciones y erotismo. En tal sentido, el silencio de la masacre es iluminada desde la desautomatización literaria. ¿Cómo narrar una masacre? Ferreira plantea la desautomatización carnavalesca con un dejo de nostalgia para despedir a sus personajes. No es una versión ideológica de la barbarie sino una versión 'literaturizada' para otorgar una nueva vida estética a los 'desaparecidos'. Es un riesgo ideológico al enfocar todo el proceso desde las historias personales de las víctimas, pero un triunfo desde la evaluación artística.

En la novela de Ricardo Silva Romero, El espantapájaros, podemos observar ciertas similitudes con la novela de Ferreira. Aquí también se narra una masacre cuya estructura es casi idéntica: un ejército armado ingresa en un pueblo llamado Camposanto, en el municipio de Montenegro a la hora de la misa, ejecutan con armas de fuego a algunos de los habitantes en la plaza, encierran al resto al interior de la iglesia y proceden a realizar una suerte de juicio a los viejos pobladores, acusados de haber formado parte de la guerrilla y esconder al Espantapájaros, un mítico guerrillero. Luego, proceden a ejecutar uno a uno a estos ancianos, públicamente, a vista del resto de los habitantes del pueblo en una especie de espectáculo teatral del horror con sumario estético de archivo incluido. La estructura del lugar es la misma: un caserío, una plaza principal, la iglesia, el consultorio, el matadero y las veredas son el escenario de la carnicería. Con un estilo hiperrealista, el narrador nos aclara que la masacre comienza el mediodía del 28 de diciembre, que dura un total de 3 horas y 59 minutos y que es acometida por el Bloque Titanes en sus cinco camiones. 
CATEDRAL TomAda: Revista de crítica literaria latinoamericana / Journal of Latin American Literary Criticism

Perspectivas múltiples del conflicto paramilitar en dos novelas colombianas recientes: Viaje al interior de una gota de Sangre (2011) de Daniel Ferreira y El espantapájaros de Ricardo Silva Romero (2012)

La principal diferencia que inmediatamente es perceptible en relación a la novela de Ferreira es que aquí los paramilitares tienen nombres y apellidos, historias, motivaciones, e incluso, son protagonistas del relato y asumen la voz narrativa en varios momentos de la historia. Sabemos que la masacre está ordenada por un tal "Doctor", dueño de todas las tierras del lugar, y será ejecutada por Over Zúñiga, alias el "Comandante Cigarra" y su ejército de 114 soldados llamado "El bloque titanes". Entre los cuales se encuentran el "Polilla" Velandia, un niño de 11 años reclutado ilícitamente que viste de soldado y juega a ser adulto, Inocencio Ríos alias "El Tumor" un ex militar del Ejército Nacional obligado a retirarse, Joaquín Fierro alias "Costra", cuñado del Cigarra, tartamudo que no tiene la confianza del batallón por su condición y Severino Baquero alias "Caifás" que enterró vivo a su propio hermano por comunista y sufre de taquicardia:

El Polilla hace cara de adulto dispuesto a morir porque, bueno, todos los días son días prestados. El Tumor grita ¡hijueputa, hijueputa, hijueputa! Para no oír las voces que le interrumpen las ideas de vez en cuando y aprieta los dientes porque esa rabia podría morder lo que fuera donde fuera. El Negro Manosalva se le acerca a él, al Cigarra, para que le ponga la mano en el hombro. Y el comandante siente que su corazón late dentro de todos sus soldados. Y en vez de repetirles la orden de atacar, asiente, simplemente asiente, en el centro de un círculo de discípulos que se ha ido formando a su alrededor. (18)

El autor le da identidad al victimario y el acceder a la psiquis y mundo emocional de cada uno de ellos genera un grado de ambigüedad en términos de comprensión del fenómeno de la violencia paramilitar y de las motivaciones que llevan a estos sujetos a convertirse en verdugos. El espesor con que son presentados 
los personajes paramilitares produce una extrañeza desautomatizadora ${ }^{6}$ en el lector pues usualmente las novelas de la violencia se enfocan en las víctimas y no tanto en los victimarios, menos en sus debilidades, miedos e inseguridades.

Por otro lado, están las víctimas. Sin embargo, y a diferencia de la novela de Ferreira, se trata de un pueblo compuesto de ancianos que han participado del período llamado de la "Violencia" realizando actos cuestionables -desde la acusación de los bandos paramilitares y de ahí la ejecución sumaria- y que reconstruyeron su vida desde cero, olvidando los presuntos crímenes del conflicto $\operatorname{armado}^{7}$. Detrás de todos ellos se encuentra la figura espectral del Espantapájaros, un mítico y gigante guerrillero que vive supuestamente gracias a la colaboración popular. De alguna manera, los personajes poseen un grado de profundidad en su construcción que permite evitar el reduccionismo entre víctimas-buenas y victimarios-malos. Son todos personas con sus propios conflictos, pecados, contradicciones y precariedades. Este es un logro de la novela de Silva Romero, el que sus personajes sean articulados desde la personalidad de los victimarios porque permite un conocimiento al que no tenemos acceso en los relatos de este tipo.

Ahora bien, independiente de la subjetivización que hace el autor de los paramilitares, eso no implica que no se sancione éticamente los actos de violencia de aquellos. El acceso a la subjetividad paramilitar permite una mayor comprensión del fenómeno al poder desarrollar más ampliamente la ideología que existe detrás de los actos que incluyen arbitrariedad racionalizada en los crímenes. Las motivaciones para asesinar son diversas: el dinero, el poder, la venganza y en algunos casos, como el del Polilla, la precariedad. Eso también permite una gradación entre maldad y relativización de la misma al interior del propio ejército paramilitar. No es lo mismo el Cigarra, comandante motivado por una ideología ultraderechista y por una venganza individual, que el Polilla, un niño de tan sólo 11

${ }^{6}$ Calificamos con un procedimiento general del formalismo ruso, la percepción extraña que es darle densidad a los personajes paramilitares en el marco de una condena generalizada de tales actores de la violencia a través de todo el archivo de las novelas en que son incluidos.

${ }^{7}$ La novela no explica si hay certeza en estas culpas o no, muestra más bien la furia y la supuesta culpa con que los paramilitares enfrentan su tarea mortuoria. 
CATEDRAL TomAda: Revista de crítica literaria latinoamericana / Journal of Latin American Literary Criticism

Perspectivas múltiples del conflicto paramilitar en dos novelas colombianas recientes: Viaje al interior de una gota de Sangre (2011) de Daniel Ferreira y El espantapájaros de Ricardo Silva Romero (2012)

años que ha sido reclutado por ser pobre y no tener una familia que se haga cargo de él. "[El polilla] sostiene al bebé como un profesional: su mamá quedaba embarazada cada vez que su tío, el bandolero, pasaba la noche en la casa, y él, de tan pocas palabras, pero con una bondad que odiaba a la muerte, pronto aprendió a cuidar a sus hermanos a punta de gestos" (24). La relativización de las culpas del niño se evidencia cuando es capturado por el Espantapájaros al final del relato. En su exhibición del paramilitarismo, el autor consigue la desmitificación de la propia figura del masacrador paramilitar. La 'banalidad del mal' se puede articular, pero ideológicamente con la versión literaria Silva Romero consigue eludir el terror invisible que ha arrojado sobre la comunidad estos actos de barbarie y de oprobio en las zonas rurales. Parte de la desautomatización de Silva Romero es deslegitimar la violencia como argumento del mito horripilante de estas acometidas. Silva la presenta diegeticamente como un relato construido de mitos, de verdades a medias, de sospechas y de articulaciones mediocres antes que del mito del fascismo extremo de la violencia pura.

\section{De multiperspectivismo a la heteroglosia en el relato paramilitar}

Para estructurar ambos textos, los autores recurren a un procedimiento especialmente relevante al relato modernista ${ }^{8}$, un perspectivismo en confluencia con un narrador básico exterior a la acción. Esto quiere decir que ambos autores utilizan un procedimiento de saturación estética que contrastaría con la "naturalidad" testimonial del relato de la violencia en el marco del conflicto armado nacional (en que probablemente disminuirían las voces para no complicar la existencia de múltiples versiones sobre un acontecimiento). Esto no constituye un demérito al interior de los textos, sino que proporciona una dignidad estética a los materiales con lo que los autores trabajan a pesar de tener una base de fuentes en masacres reales, lo que probablemente hubiera incrementado el uso de una lógica documento-testimonial. Este perspectivismo parcial (al menos de tipo cognitivo si quien habla es el narrador básico) dota tanto de una voz e historia a las víctimas lo

\footnotetext{
${ }^{8}$ Nos referimos a la novela de perspectivismo múltiple como en William Faulkner y James Joyce.
} 
que le da una memoria a la cifra fría y cruel de cadáveres. Esto es evidente en el caso de Ferreira y también en Silva Romero, quien transforma a los victimarios como Cigarra9. Los discursos de los narradores y de los personajes en su confluencia otorgan un sentido estético y, pensamos, un sentido ideológico. En tanto estético, se observa una muestra de los logros complejos que posibilitan esta "exageración" inaudita de hacer proliferar las voces de los intervinientes en la masacre como un fenómeno colectivo. En tanto ideología, la consciencia plural "democratiza" el relato con sus voces, da una respuesta ideológica a la masacre silenciosa, y permite a los lectores tener una dimensión densificada de los fenómenos al observar el corte transversal con que se ha reconstruido aquel archivo invisibilizado de las masacres. Por una parte, contar las historias de las víctimas en Ferreira, por otra y de modo más interesante, contar las vidas furiosas de los victimarios en Silva Romero. Los autores según la versión propuesta colocarían en una dimensión bajtiniana ${ }^{10}$ esa masacre al modo de una "carnicería de voces". Con este procedimiento, que se puede asociar a la polifonía, se pulveriza ese silencio instituido a puertas cerradas de los escasos testimonios que quedan de las masacres reales cometidas en los pueblos. Frente a la crueldad de los eventos reales, los autores nos hacen partícipes de un evento lingüístico en que víctima y victimario tienen voces diferentes, crueles, temerosas, inocentes que son escrutadas desde una evaluación ideológica de los fenómenos. Recordemos que no son fenómenos reales sino mimesis estéticas y creemos que tanto Ferreira como Silva Romero pretenden que no obviemos esta situación. Sin embargo, lo que en la extra diégesis es la desaparición de los cuerpos, en la representación literaria es articular un nuevo contrato con la palabra novelesca a través de una versión ficcional que exagera la puesta al desnudo del procedimiento literario perspectivista. Aquí la cifra y la localización exacta (la versión que cuenta el número de los sujetos asesinados, pero

${ }^{9}$ Casi como un personaje de tragedia griega en tanto determinismos de destino. Lo que no significa exculpar de las barbaries que cometen en las localidades.

${ }^{10}$ No deja de llamar la atención que Bajtín halla imaginado la posibilidad del discurso monoglósico como una cárcel de tortura nazi silenciosa. Aquí nuestra extensión es imaginar que esas masacres en los pueblos colombianos establezcan una dimensión paralela al silencio de la violencia paramilitar sobre el exterminio producidos en las masacres. 
CATEDRAL TomAda: Revista de crítica literaria latinoamericana / Journal of Latin American Literary Criticism

Perspectivas múltiples del conflicto paramilitar en dos novelas colombianas recientes: Viaje al interior de una gota de Sangre (2011) de Daniel Ferreira y El espantapájaros de Ricardo Silva Romero (2012)

no sus historias personales) se pierden en pro de elementos (des)mitologizadores, de voces comunitarias e individuales, de victimarios y víctimas. ${ }^{11}$ Aunque se corra el riesgo de la incomprensión y de la excesiva saturación estética para que la lectura de la evaluación ideológica implícita pueda ser descubierta e interpretada adecuadamente.

Un breve análisis desde la perspectiva estudiará estas voces desde víctimas a victimarios. Se puede exponer un criterio que se llamaría heteroglósico desde la teoría de la novela bajtiniana. Esa heteroglosia o múltiples niveles permiten discriminar si ambas novelas tienden a un registro en consonancia con lo que Bajtín denomina como orquestación social de voces al interior de la novela ${ }^{12}$. En ese sentido, la obra de Ferreira quedaría más cercana al intento de Evelio Rosero ya que su nivel estilístico termina siendo uniforme como registro estético respecto a la variedad ideológica expuesta por Silva Romero. Este último quizás tampoco alcance los niveles heteroglósicos como son expuestos por Bajtín (como voces y evaluaciones múltiples que responden a una heterogeneidad de discursos sociales), pero sí se aproxima a un modo más plural, al incluir la voz de los victimarios. En ese sentido, la presencia/ausencia del guerrillero espantapájaros en su mitologización heroica (y su ausencia del relato casi hasta el desenlace) favorece la acción múltiple de las otras voces.

Hay un discurso de control ideológico del narrador, ya que en las dos novelas se presenta el relato en forma de discurso impersonal para abrirse a esta posibilidad de versiones cognitivamente individualizadas: "Yo me llamo Over Zúñiga -dice con la modestia tramposa de un gamonal- y estoy aquí porque sé que muchos de ustedes no se merecen este lugar, porque sé que a muchos de ustedes se les ha dado la mano y se han tomado hasta el codo." (Silva Romero 27). Este ejemplo permite reconocer la evaluación adjetiva del narrador externo que escapa a la percepción de Over Zúñiga/el Cigarra. En Ferreira si se aprecian los victimarios

11 Entendemos eso como un gesto 'político' en que Ferreira y Silva Romero desmontan estéticamente el 'impío' mecanismo de la masacre/ficción

${ }^{12}$ La multiplicidad de voces y registros sociales es lo que en una época concreta en Bajtín funciona como la heteroglosia o discursividad social. 
es en la orden del matarife, quien se escucha o se siente a través el temor es la víctima:

Diez minutos después de la primera balacera, aquellos que intentaron atravesar la plaza y siguen heridos reciben un tiro de gracia en la nuca. Los que se lanzaron de bruces, para protegerse del curse de disparos, se oprimen las cabezas de pensar en que ahora también ellos serán rematados.

Como tal no hay lugar para la multiplicidad de planos sociales sino el silencio de la masacre hasta que no interviene la voz fantasmal de cada víctima seleccionada. La perspectiva en Ferreira es de quien siente esa bala de remate, mediado todo por el control evaluativo del narrador externo a la acción. El capítulo introductor "La hora de las sombras largas" sirve desde la narrativa impersonal para mostrar el choque ideológico entre la fiesta del pueblo y la llegada de la muerte a través del comando paramilitar que interrumpe sangrientamente la festividad. La perspectiva impersonal muestra un alcance comunitario del grupo local festejado a punto de ser interrumpido -y silenciado- por el comando. Luego, el Capítulo "Las mujeres locas que asesinaron a Orfeo" sí es narrativa personal del niño anónimo, amigo del niño ahorcado en la masacre Pedrarias, que escapa a la muerte accidentalmente y que espiaba voyeuristamente a las muchachas del pueblo cuando se bañaban. Este niño no por casualidad reaparecerá en final, acaso por la unción que hace Ferreira, entre Eros y Tánatos, respecto al beso erótico posmortem que él brinda a la muchacha asesinada. Después, tanto la historia de "La bañista" Irigna Delfina como la de "El último bolchevique" con el profesor Arquímedes también están en control del narrador básico. Mientras que en la historia de "El hotel" con el niño y su madre, desde una perspectiva adulta del niño, vuelve por los fueros de la narrativa personalizada. En tanto, la historia de "Divagación al pie de la horca" en que Urbano Frías escapa de la matanza, opta por una mezcla de relato impersonal con voz de la angustia del personaje por sobrevivir. Ya, en "Una hoguera para que 
CATEDRAL Tomada: Revista de crítica literaria latinoamericana / Journal of Latin American Literary Criticism

Perspectivas múltiples del conflicto paramilitar en dos novelas colombianas recientes: Viaje al interior de una gota de Sangre (2011) de Daniel Ferreira y El espantapájaros de Ricardo Silva Romero (2012)

arda Goya" se muestra el padre Bernardo acosado por el grupo paramilitar y acusado como cura comunista, otra vez en relato impersonal del relator externo. Espacial y psicológicamente el relato se focaliza en la mente del sacerdote enfrentado a los victimarios protegido en la iglesia. En el capítulo final, a modo de testigo y sumario absolutamente en control de la narrativa impersonal, tendremos al niño testigo de la devastación que ha dejado la masacre y el fin de aquella ante el fuego destructor que aqueja a su propia casa. Las separaciones en capítulos con nombres bien definidos -a veces estilísticos en extremo- en Ferreira ya nos indica esa apuesta del narrador / autor por ejercer un control masivamente desde un relato impersonal que a veces cede la palabra a algunas de las víctimas.

En cambio, Ricardo Silva Romero, no coloca nombres a los capítulos, los fragmentos se aíslan por espacios en blanco. Y la diferencia es que lo buscado a diferencia de los niños, adolescentes, bañistas y el eros que campea en la novela de Ferreira son los viejos que incluso ya han olvidado sus culpas pretéritas. Viejos serán las víctimas, cansadas y fusiladas, y ya en su decrepitud, el mitologizado “espantapájaros". La mirada de la ancianidad -el cansancio de tanta violencia- está muchísimo más presente en la novela de Silva Romero y por eso se percibe a adolescentes casi niños titubeantes en el relato a través de la tropa del Bloque Titanes comandada por el Cigarra. El Comandante Cigarra asume la voz narrativa intercaladamente en la historia de modo tan pleno que a veces incluso se confunde con la voz del narrador omnisciente que aparece en ciertos momentos. La subjetividad del Cigarra queda expuesta al lector y permite ver cómo observa el mundo y cuál es su modo de ser en el mismo “¿Y si llevara al viejo Rogelio hasta el altar a cortarle la cabeza en nombre de todos y poquito a poquito para que el viejo hijueputa sepa mientras va muriendo que le están cortando la cabeza?” (26). La crueldad del personaje queda expuesta en las reflexiones que hace durante la masacre. Lo mismo sus opiniones políticas, que generalmente coinciden con una ideología de extrema derecha, (auto)engañándose en el rol de una suerte de justiciero histórico que viene a hacer pagar a aquellos que han cometido errores y corregir el rumbo de la historia del país: 
Quiere llenarse los pulmones de ese miedo que se vuelve cólera como un monstruo que vive de la sangre de los otros, como un perro con jirones de carne colgados de sus dientes salvajes, pero el aire se ha quedado quieto en la calle empinada que atraviesa el poblado. Toda la tropa del Bloque Titanes lo mira a la espera de la orden. (11)

De este modo, los victimarios son representados de diversas formas, desde el líder desquiciado del escuadrón hasta el niño semi-inocente o incluso el Caifás que termina arrancando de la masacre por miedo y por, curiosamente, enamorarse de la enfermera del pueblo. A lo largo de la novela y, mediante el control del narrador impersonal de la historia, escuchamos esa historia que se ha forjado en el pasado de la venganza del Cigarra contra el Espantapájaros. Y la historia permite abrirse cognitivamente al registro de los personajes y sus motivaciones. Por lo que en medio del desastre se permite el narrador de Silva Romero algunas ironías y torpezas de sus actores. Él es el titiritero de todas las acciones y presentaciones, pero algo tienen que decir ellos desde sus miradas forjadas en un tiempo anterior. Y el pretérito cobra un sentido respecto al lugar de acción del espantapájaros y de los ancianos condenados por el bloque paramilitar. Así, el control ideológico queda mucho más abierto que en Ferreira, donde la "(in)verosimilitud” poética compite con el desastre de la masacre. Ciertamente quien tiene las armas tiene el control se deduce de la lógica de Silva Romero- y el autor no escabulle la responsabilidad de la matanza del grupo paramilitar -pero juega con la ambigüedad de la cognición individual de cada matarife- contra los ancianos seleccionados en el plan previo de la masacre que ya está anunciada al inicio de toda la novela. Y que sigue presente en todo el relato cuando el Cigarra hace una cartografía del pueblo Camposanto e invita mentalmente a los jóvenes al escarmiento del fusilamiento de los ancianos y recuerda los lemas de su profesor de historia Espinel, tergiversando la pregunta por la memoria por una respuesta desde la venganza y la justificación de la masacre a 
CATEDRAL TOMADA: Revista de crítica literaria latinoamericana / Journal of Latin American Literary Criticism

Perspectivas múltiples del conflicto paramilitar en dos novelas colombianas recientes: Viaje al interior de una gota de Sangre (2011) de Daniel Ferreira y El espantapájaros de Ricardo Silva Romero (2012)

acometer. "Porque, como decía el profe Espinel, un pueblo que no sabe nada de su pasado está destinado a revivirlo" (86):

Y él mismo ha dejado de ser Over Zúñiga para convertirse en el comandante Cigarra, como una avalancha que se veía venir si se miraba con cuidado, cada vez que se le ha puesto esa tarea en su destino. El señor Espinel, su profesor de Historia de cuando todavía iba a la escuela, dijo una vez que ciertos hombres vienen al mundo a hacer la guerra. Tenía razón. (52)

Y llega en diez páginas el sumario y el fusilamiento de los ancianos acusados de encubridores y participantes de la guerrilla:

El comandante espera a que la plaza quede como la ha imaginado todos estos días antes de irse a dormir. Ya está. Ya está igual. Así los quería ver: con esas caras, con esos fusiles, apuntándole al que venga, con esas manos con un disparo marcado en la línea del destino.

Nada ni nadie imagina una masacre. Pero eso era, exactamente, lo que tenía en mente: lo único que queda en la plaza de Camposanto, bajo la nube negra, es él y su ejército que encierra a veintinueve viejos condenados a muerte. (122-23)

Finalmente, el plan de varios años de el Cigarra empieza a cumplirse. Dispone a los ancianos para el fusilamiento y la masacre se cumple. Destaca que entre las opciones estilísticas, el narrador de la novela opte por sumarios breves en que se registra cada caso del condenado. El uso de este procedimiento constituye una ironía cruel, en que el propio autor Silva Romero cuestione el archivo documental sobre las muertes. Ciertamente el registro llama la atención de nosotros los lectores y permite desautomatizar el registro de archivo y la cifra desnudando la crueldad inútil del archivo estadístico. La cifra es desnudada en su envés por la 
palabra literaria ambigua y que puede ser sometida a un escrutinio distinto o de mutaciones históricas diferentes. Como dice el lingüista Dominique Maingueneau, la palabra literaria es opinión e interpretación de la realidad. Ese aserto evaluativoideológico aparece representado en el uso de saturación estética del multiperspectivismo especialmente en Silva Romero.

En general, en El espantapájaros existe una cesión de la palabra a medias a los personajes. Como un actor privilegiado es el Cigarra, quien es recurrente como conciencia de este discurso ajeno:

Todo el año les dijo: "estas tierras son de quien son", "el dueño las quiere para construir un parque", "manda a decir el doctor que se vayan por las buenas". "Si no se van, van a pagarlo". Pero ellos se portaron como se portan los viejos: se encogieron de hombros, dijeron, palabras más, palabras menos, "nada puede hacerse contra la naturaleza cuando a la naturaleza le da por ponerse en contra de uno", como esas familias que en los años cuarenta prefirieron morir sofocadas en sus casas bajo el río Montenegro. (52)

En este fragmento se aprecia la imbricación del discurso del narrador básico con las evaluaciones del Cigarra. Y la conciencia de Over Zúñiga/Cigarra justificando sus acciones antes de la masacre a través de las advertencias para ceder las tierras al Dueño. El cigarra parece libre para actuar y pensar, pero no es así porque es desde ese lugar que el narrador básico revela los miedos, la actitud vengativa y nos muestra fundamentalmente a Over Zúñiga y no "el Cigarra" temido por sus subordinados. En aquel sentido, el uso de los nombres distintos también es señalado como un elemento ideológico para la percepción de las conciencias según Uspenski, lo que se vería fuertemente legitimado por la conciencia fantasmal del 'espantapájaros' otro seudónimo, en este caso, para el guerrillero mitificado.

Algo parecido sucede con los otros sujetos integrantes paramilitares. Son un grupo asesino que viene a buscar a unos ancianos y al "espantapájaros". El 
CATEDRAL Tomada: Revista de crítica literaria latinoamericana / Journal of Latin American Literary Criticism

Perspectivas múltiples del conflicto paramilitar en dos novelas colombianas recientes: Viaje al interior de una gota de Sangre (2011) de Daniel Ferreira y El espantapájaros de Ricardo Silva Romero (2012)

narrador desautoriza al comando al convertirlos en sujetos masacradores y ‘deslegitimando' su versión mitificada (en la cual incluye al espantapájaros). La masacre es cruel, injustificada y vesánica pero ellos como grupo son absolutamente anárquicos y precarios. La semántica de la representación de la masacre para el autor Silva Romero es destruir el núcleo dominante del victimario. Ello desde una conciencia que posee voces individuales pero también un control exterior desde el narrador básico que deshabilita evaluativamente este asesinato masivo. Lo que aparentemente es un exceso en Silva Romero para hacer hablar teatralmente al Cigarra o al Polilla, es un artificio muy original para desautomatizar literariamente la representación de las masacres y el punto de vista épico de otorgarle voz y homenaje póstumo a las víctimas. Esta es una perspectiva aguda para confrontar las versiones oficialistas de las masacres.

Mientras que la cesión de la palabra del personaje está más ausente en Viaje al interior..., por ejemplo, en el capítulo de la voz del profesor se habla de "Gran Rebelión Bolchevique" (71), en que aparece en cursivas el lenguaje técnico del mitin con los obreros "producción, plusvalía y fuerza de trabajo.... El capital” (73); "Obrero camino a la servidumbre, etc." (75); en que la autoría se hace una con la mirada del profesor Arquímedes y en que su ironía revela la postura autorial respecto a la inclusión compleja de los discursos sociales. Aquí el lenguaje del mitin sindical es lenguaje ajeno al texto. "La mayoría de aquellos hombres eran analfabetos, y quizás por eso blandían con desinterés los volantes cuando se los pasaban de mano en mano para su debida discusión en círculos de estudio" (73). Así como esta circularidad lingüística es visible en el cierre del texto con la perspectiva del niño, en general, Ferreira utiliza las comillas para mostrar el lenguaje ajeno y los diálogos para el acceso a la voz ajena. Eso ocurre, por ejemplo, en el diálogo agresivo entre el mendigo ciego y el paramilitar asesino. " ¡¡Repítalo, malparido! -y el cañón del fusil le apunta a la frente. / -Me lo chupa, me lo mama, me lo trompetea -dice el mendigo. /-Aquí te vas a morir, cegatón -dice el encapuchado. /-¡A culiar, que el mundo se va a acabar! -exclama el mendigo" (21). 
Los murales pintarrajeados del recuerdo también aportan con ese lenguaje ajeno cuando se apuntan “¡Fuera ratas milicianas!”, “¡Muerte a coordinadora campesina!”, “زFuera cura guerrillero!” (98). El discurso ajeno carnavaliza el lenguaje pseudo oficialista del integrante paramilitar desde esos lugares del discurso social de la conciencia pluralizada que explora Bajtin.

En algún punto de encuentro, ambas novelas desautomatizan el lenguaje de la cifra, el de la memoria y el de la masacre victimizadora de los comandos paramilitares. En una apuesta arriesgada ideológicamente, para hacer más visible el discurso ajeno, Silva Romero presenta a las víctimas como un conjunto de ancianos que en tiempos idos podrían haber sido guerrilleros pero que en el presente son víctimas indefensas del furioso Cigarra. Esto se refuerza con que el alto y mitificado espantapájaros no es más que el ex guerrillero temible, y en el presente, un sobreviviente escondido en unas cuevas. Para contar la historia, aunque no retrocede en la autoridad legitimadora del narrador básico, el discurso ajeno, curiosamente se posiciona en el lugar del victimario. Esto provoca una mirada extraña del acontecimiento ya que se objetualiza el mundo de la víctima y el del espantapájaros pero el efecto se ha conseguido. En cuanto apropiación estética, la novela de Silva Romero hace extraño el lenguaje de la muerte cuando desnuda con diferentes matices los códigos lingüísticos del comando. No podemos dejar de pensar en los trucos de Borges respecto a la perspectiva del traidor para contar la historia, pero aquí no hay misterio policial alguno: el sujeto paramilitar es cruento y dispone de voz con la que expresarse, sojuzgado y cuestionado, eso sí, por la instancia del narrador básico extradiegético. En cambio, Ferreira con un control absoluto y estetizante, cede lo cognitivo a veces a las víctimas que son presentadas en todos sus matices y no son heroificadas. Sin embargo, el control autorial y el lenguaje altamente estilizado atrapa en una 'cárcel del lenguaje' homogéneo a las víctimas. El masacrador no tiene voz y la víctima espera el momento en que cognitivamente el narrador básico le de pie a contar su historia, con la regular e impactante entonación estética de toda la novela. 
CATEDRAL TomAda: Revista de crítica literaria latinoamericana / Journal of Latin American Literary Criticism

Perspectivas múltiples del conflicto paramilitar en dos novelas colombianas recientes: Viaje al interior de una gota de Sangre (2011) de Daniel Ferreira y El espantapájaros de Ricardo Silva Romero (2012)

En un primer momento de su reflexión, el plano o nivel que Boris Uspenski denomina nivel ideológico o evaluativo, el semiólogo se pregunta por la coincidencia del discurso ideológico del narrador con sus personajes. Si se atiende a estas preguntas, ciertamente no atribuimos la coincidencia del narrador exterior con los masacradores de las novelas (los sujetos paramilitares). Esto será explícito en Ferreira al relatar desde las víctimas, pero cuesta más identificarlo intuitivamente en las historias de Silva Romero. En el caso de Ferreira, establece algún grado de coincidencia con el niño voyeurista y acaso ideológicamente como un héroe silencioso con el "último bolchevique", el profesor Arquímedes. Pero el tono de control básico está dado desde el inicio con esa visión omnividente: “Al sobrevenir el aplauso de la multitud, nadie se imagina que aquellos cinco músicos van a ser los primeros que caerán en la matanza" (18). Mientras que en Silva Romero también al inicio: "Y los primeros disparos al aire, que vienen de cinco furgones viejos, repletos de asesinos, de visita en el poblado como una marcha fúnebre que colecciona cadáveres, despejan la duda de si volverá a empezar una tragedia que empezó hace mucho tiempo" (7), en donde hay una evaluación de parte del narrador básico que involucra incluso la historia de Colombia con el comentario sobre la 'tragedia' que viene de muchos años atrás. Y menos de Cigarra el comandante en que el narrador puede mostrarnos sus pensamientos: "Y entonces recupera la ira: si algo odia en este mundo, si algo le revuelve el estómago a él, al Cigarra[...]" (49). Entonces a la vez que hay una distancia del narrador básico con los personajes (clarísimo respecto al sujeto paramilitar, más cercano con algunas de las víctimas en Ferreira), ideológicamente existe una distancia evidente desde el nivel evaluativo. Pero no una condena panfletaria desde el lugar de la absoluta monstruosidad de violencia fascista. Si junto con Uspenski se suma a Bajtín ${ }^{13}$, se puede explorar variadas conciencias ideológicas y en Ferreira se tendrían versiones individuales y desde conciencias cognitivas heterogéneas relativa a las diferentes víctimas, mientras que una línea homogénea en los perpetradores de la masacre. Esto con la posibilidad de cotejar la conciencia de los personajes con la evaluación

\footnotetext{
${ }^{13}$ A propósito de la polifonía novelesca.
} 
personal que propone el narrador básico. Mientras que en Silva Romero, se explorara la conciencia del espantapájaros, los varios integrantes paramilitares, el narrador básico y como unos subgrupos específicos tanto los sacerdotes y los niños. Esta conciencia ideológica plural nos acerca en otro plano de análisis a la heteroglosia propuesta por Bajtín como conciencia polifónica interna a la novela. Acercar al descubrir varios planos estilísticos que conduzcan a varias conciencias sociales. Esto es más perceptible en Silva Romero que en Ferreira.

Como resumen, se puede complementar en tanto conciencias ideológicas a los personajes, el autor y el narrador y aquello que importa en el plano de la evaluación (como dice Bajtín citado por Uspenski), consiste en cuál es el mundo para los personajes o actores literarios (y participantes comunicativos de las novelas como el narrador). Por eso se partía de ese lugar en que nadie se siente representado ideológicamente en estos textos estéticos por los sujetos paramilitares ${ }^{14}$. Pero las opciones en ambos textos cuando se cede la palabra, se presentan radicalmente en el caso de Ferreira al asumir el lugar de las víctimas de muy distinta edad, género, profesión, etc., y sobre todo al explorar como evaluación ideológica la historia de estas víctimas silenciadas. En cambio, la perspectiva de Silva Romero es más incómoda, aunque no comparte la versión paramilitar y lo deja claro con el calificativo de asesinos, no por eso se priva de explorar la conciencia del sujeto criminal. Así como también en Silva, los fragmentos de ideología paramilitar y la obsesión por el espantapájaros y los ancianos del pueblo. Para otro momento, se dejará una pregunta por la versión ideológica del llamado 'héroe' novelesco como conciencia portadora de ideología, ¿cuáles serán los héroes específicos que portan una ideología dominante en cada novela? Ciertamente habría que determinarla en Ferreira o en Silva Romero, ¿será el Cigarra o el Espantapájaros o quién? ¿De qué modo el narrador interactúa con esa conciencia evaluativa personalizada?

\footnotetext{
${ }^{14}$ Lo que curiosamente resuelve inmediatamente un lugar ideológico a considerar en las novelas, se observa desde el exterior de la conciencia del sujeto paramilitar.
} 
CATEDRAL Tomada: Revista de crítica literaria latinoamericana / Journal of Latin American Literary Criticism

Perspectivas múltiples del conflicto paramilitar en dos novelas colombianas recientes: Viaje al interior de una gota de Sangre (2011) de Daniel Ferreira y El espantapájaros de Ricardo Silva Romero (2012)

\section{Conclusión}

Tanto la novela de Ferreira como la de Silva Romero confluyen en que se encuentran saturadas de contenido estético a pesar de la referencialidad ligada a masacres colombianas de grupos paramilitares. En ambas obras se asiste a la descripción detallada de tales acontecimientos que constituyen una síntesis de eventos que ocurrieron en la referencialidad de los asaltos a los pueblos. Una mezcla de episodios tales como la Masacre del Salado, la de Mapiripán o cualquier otra de las múltiples matanzas que ejecutaron aquellos grupos y cuyos elementos son reconocibles como un archivo de la memoria. La diferencia estriba en que la novela de Silva Romero permite una mirada más compleja y político-ideológica sobre el fenómeno al permitir acceder a la subjetividad de los sujetos involucrados en las masacres paramilitares, tanto víctimas como victimarios. Esto se produce porque su lenguaje desautomatiza el discurso al volverlo pluralidad de voces sociales y permite una lectura política de los acontecimientos incorporando niveles y clases sociales deprimidas desajustando la mirada víctima / victimario y masacre / silencio en pro de la emergencia de esos discursos sociales múltiples. Ferreira, por su parte, ha optado por una mirada sobre las víctimas en una polifonía de voces absolutamente controlada por el narrador exterior a la acción. Pero su registro estilístico no solo es uniforme, sino que 'estetiza' el lugar de la víctima en demasía lo que neutraliza el rol de la evaluación ideológica implícita y esperable en un relato plural como aquel o que tendería a lo que aproximamos como la heteroglosia ${ }^{15}$. En ambos casos, Ferreira y Silva Romero, se desarrolla una propuesta desde el control del narrador básico y la cesión parcial a personajes víctimas y personajes victimarios. Sin embargo, el proceso de desautomatización de Silva Romero logra un mejor efecto ideológico-político al destituir la mitificación de la crueldad inhumana de los paramilitares y del mismo mito-guerrillero que da nombre o

${ }^{15}$ En tal sentido, un modo apropiado de reflexionar sobre estos eventos literarios es evaluarlos desde la distancia de la multiplicidad de los registros lingüístico-sociales o 'heteroglosia' bajtiniana. La heteroglosia obliga a una mayor exposición de los discursos sociales acompañados de registros estilísticos de la variedad social. 
epíteto a la novela el 'espantapájaros' ${ }^{16}$. Mientras que en Ferreira la apuesta por la víctima se recubre de un lenguaje estilizado pero monosémico. Eso sí, a ambos les faltan elementos para mostrar el mundo heteróclito de las voces sociales, ya que ambos cierran el universo ficcional en el control autorial básico de un narrador externo ${ }^{17}$.

Para finalizar, una reflexión general: en épocas del llamado 'posconflicto', se observa la aparición de estos proyectos estético-literarios que recrean episodios de violencia específica como la masacre paramilitar con actitudes disímiles entre sí, con técnicas, puntos de vista y procedimientos distintos. Este conjunto de autores, que van desde los más canónicos como Evelio Rosero o Santiago Gamboa, a autores en proceso de canonización como Ferreira o Silva Romero, y que continúa con muchos otros, se han decidido a representar este episodio particular de la violencia colombiana de manera contundente. Entonces, la reflexión es por el ejercicio literario como memoria estilística o memoria textual, que desestabiliza los discursos hegemónicos neutralizantes, como un contradiscurso que llama y exige una respuesta evaluadora-literaria de los lectores respecto a la referencialidad del archivo nacional. Ahora con certeza se desvanece la pregunta por la responsabilidad de hacer literatura de las masacres. ¿Se puede representar narrativamente el asesinato de colectivos y relatar abiertamente episodios de violencia física y destrucción del cuerpo de las personas? Por supuesto, al menos la respuesta ideológico-estética de ambos autores se abre a una representación estilísticoideológica que enriquece el archivo de la memoria oficial histórica de tales eventos.

Por supuesto como críticos aventuramos una opción literaria de evaluación ideológica en función de las desautomatización que ambos relatos utilizan para reconstruir las masacres, debido a la pluralidad de conciencias ideológicas involucradas y el lugar político con el que el lector debiera intervenir para

\footnotetext{
${ }^{16} \mathrm{Y}$ esto se comprueba con que las víctimas son un grupo de ancianos indefensos que son un resabio de un heroísmo inútil.

${ }^{17}$ En esas autorrestricciones estéticas de los dos autores, la voz de los masacradores de Silva Romero suena más verosímil estéticamente desde la evaluación social que la voz del narrador víctima de Ferreira.
} 
CATEDRAL TomADA: Revista de crítica literaria latinoamericana / Journal of Latin American Literary Criticism

Perspectivas múltiples del conflicto paramilitar en dos novelas colombianas recientes: Viaje al interior de una gota de Sangre (2011) de Daniel Ferreira y El espantapájaros de Ricardo Silva Romero (2012)

reconstruir las motivaciones y las historias detrás de cada evento de la masacre presentado.

\section{Bibliografía}

Bajtín, Mijaíl. La novela como género literario. Zaragoza: Prensas de la Universidad de Zaragoza, 2019.

Burucúa, José Emilio y Nicolás Kwiatkowski, "Cómo sucedieron estas cosas". Representar masacres y genocidios. Buenos Aires: Katz, 2014.

Cardona Cháves, Juan Pablo (2014). "Tres hipótesis acerca del fenómeno para militar en Colombia", localizado en https://revistas.unal.edu.co/index.php/peju/article/view/48904/pdf_25

Duncan, Gustavo. Los Señores de la Guerra. De Paramilitares, Mafiosos y Autodefensas en Colombia. Bogotá: Planeta, 2006.

Ferreira, Daniel. Viaje al interior de una gota de sangre. Bogotá: Alfaguara, 2011.

Mbembe, Achille. Necropolítica. Santa Cruz de Tenerife: Melusina, 2011

Romero, Mauricio (2003) Paramilitarismo y Autodefensas 1982-2003. Colombia: Editorial Planeta.

Ronderos, María Teresa. Guerras recicladas. Una historia periodística del paramilitarismo en Colombia. Bogotá: Aguilar, 2014.

Rosero, Evelio. Los ejércitos. Barcelona: Tusquets, 2007.

Santos, Danilo e Ingrid Urgelles: "La violencia paramilitar en la narrativa reciente de Colombia", Hispamérica: Revista de literatura, $\mathrm{N}^{\mathrm{o}}$ 139, 2018. 37-45.

Sémelin, Jacques. Purificar y destruir. Usos políticos de las masacres y genocidios. Buenos Aires: UNSAM EDITA, 2013.

Silva Romero, Ricardo. El espantapájaros. Bogotá: Alfaguara, 2012.

Uspenski, Boris. A Poetics of Composition. The structure of the Artistic Text and Typology of a Compositional Form. Trad. Valentina Zavarin y Susan Wittig. Los Angeles, California: University of Berkeley, 1973. . "Los 'puntos de vista' en el plano de la psicología". Revista Criterios (La Habana), traducción Desiderio Navarro, 5/12, 1984. 71-95.

(cc) EY

ULLS D-Senke
New articles in this journal are licensed under a Creative Commons Attribution 4.0 United States License.

This site is published by the University Library System, University of Pittsburgh as part of its D-Scribe Digital Publishing Program and is cosponsored by the University of Pittsburgh Press. 